\title{
ADH Genotypes and Alcohol Use and Dependence in Europeans
}

\author{
J. B. Whitfield, B. N. Nightingale, K. K. Bucholz, P. A. F. Madden, \\ A. C. Heath, and N. G. Martin
}

\begin{abstract}
We have tested for effects of alcohol dehydrogenase (ADH) genotypes on self-reported alcohol consumption and symptoms of alcohol dependence, recorded on three occasions up to 15 years apart, in 377 male and female subjects of European descent. ADH2 genotype had significant effects on both consumption and dependence in the men, but not in the women. The effects of $A D H 3$ genotype were considerably less than those of $A D H 2$, but significant results could be demonstrated when the combined genotypes were considered. The direction of the effects on alcohol consumption and dependence risk were consistent with reports on Asian subjects, and with the in vitro properties of ADH isoenzymes. As with previous studies on the relationship between ADH type and alcohol use, population stratification cannot be excluded as a contributing factor in these results.

Key Words: Alcohol Dehydrogenase, Alcoholism, Association, Female, Male.
\end{abstract}

$\mathbf{M}$ ULTIPLE REPORTS ${ }^{1-9}$ indicate that alcohol dehydrogenase $(A D H) 2$ and $A D H 3$ genotypes influence the risk of alcohol dependence among Japanese or Chinese subjects, independent of aldehyde dehydrogenase $(A L D H)$ genotype. ${ }^{1,3,4,6}$ Meta-analysis of these reports ${ }^{10}$ shows that the relative risk for alcohol dependence increases $\sim 3$-fold for each copy of $A D H 2 * 1$ and a similar amount for each copy of $A D H 3^{*} 2$ - but, on present evidence, in Asians only.

The alleles associated with lower risk $\left(A D H 2^{*} 2\right.$ and $A D H 3^{*} 1$ ) code for proteins with greater in vitro enzymatic activity. ${ }^{11}$ This is consistent with the hypothesis ${ }^{2}$ that faster conversion of ethanol to acetaldehyde deters subjects from alcohol consumption, although it has not yet been demonstrated that acetaldehyde concentrations are higher nor that ethanol metabolism is faster in vivo in subjects with these forms of $\mathrm{ADH}$. From the in vitro data, the effect of $A D H 2$ type should be greater than that of $A D H 3$ so that the

From the Department of Clinical Biochemistry (J.B.W., B.N.N.), Royal Prince Alfred Hospital, Sydney, Australia; Department of Psychiatry (K.K.B., P.A.F.M., A.C.H.), Washington University School of Medicine, St. Louis, Missouri; and Queensland Institute of Medical Research (N.G.M.), Brisbane, Australia.

Received for publication March 6, 1997; accepted June 2, 1998

The Alcohol Challenge Twin Study and initial stages of the follow-up of twins were funded by the Australian Associated Brewers. Later stages of follow-up, and genotyping, were supported by the National Health and Medical Research Council of Australia, which also supports the Australian National Health and Medical Research Council Twin Registry. Interviews were supported by Grant AA07535 from the National Institute on Alcohol Abuse and Alcoholism.

Reprint requests: J. B. Whitfield, PhD., Department of Clinical Biochemistry, Royal Prince Alfred Hospital, Camperdown NSW 2050, Australia.

Copyright (C) 1998 by The Research Society on Alcoholism. order of rates of alcohol metabolism would be $A D H 2 * 22>$ $12>11$ and within each $A D H 2$ group $A D H 3^{*} 11>12>22$. On this hypothesis, the risk of alcohol dependence, or the quantity of alcohol used and the number of problems encountered, would trend in the opposite direction.

However, studies on $A D H 2$ genotypes in other, nonAsian populations have produced negative results. ${ }^{12-15}$ This might be because of the low prevalence of $A D H 2 * 2$ in non-Asian groups, or because of some factor that modifies the effects of genotype and that differs between populations. For $A D H 3$, there are indications ${ }^{10}$ that the significant effects found in Asian populations do not extend to European ones. Therefore, it is desirable to assess the effects of $A D H$ genotype in diverse non-Asian groups in order to determine whether these effects are universal.

We have data on lifetime prevalence of alcohol dependence, together with measures of alcohol consumption and alcohol-related problems, in a group of subjects of European descent studied on multiple occasions over the past 19 years. We have therefore tested for association between $A D H 2$ or $A D H 3$ genotype and these alcohol-related variables, and the expected trend across $A D H 2 / A D H 3$ haplotypes.

Because we have tested for association between genotype and phenotype, a positive result could be produced by population stratification. This can occur if two or more ancestral populations are represented in the sample, and one genotype is overrepresented in a subgroup that happens (for unrelated reasons) to drink either more or less than other subjects in the sample. However, this problem may also have occurred in the studies ${ }^{1-9}$ that have shown $A D H$ effects on alcohol dependence in China or Japan.

Our study group differs from those in most previous reports, which have been based on recruitment of patients diagnosed as having alcohol dependence rather than assessment of quantity and frequency of alcohol use or the number of alcohol-related problems encountered. Also, in previous reports, the majority of subjects have been men and possible sex differences in the effects of $A D H$ variation have not been examined.

\section{SUBJECTS AND METHODS}

Four hundred twelve adult male and female twin subjects (206 pairs) were recruited in Sydney and Canberra in 1979 to 1981 for a study of genetic and environmental influences on alcohol metabolism and susceptibility to intoxication. ${ }^{16,17}$ At that time, their ages were between 18 and 34 , 


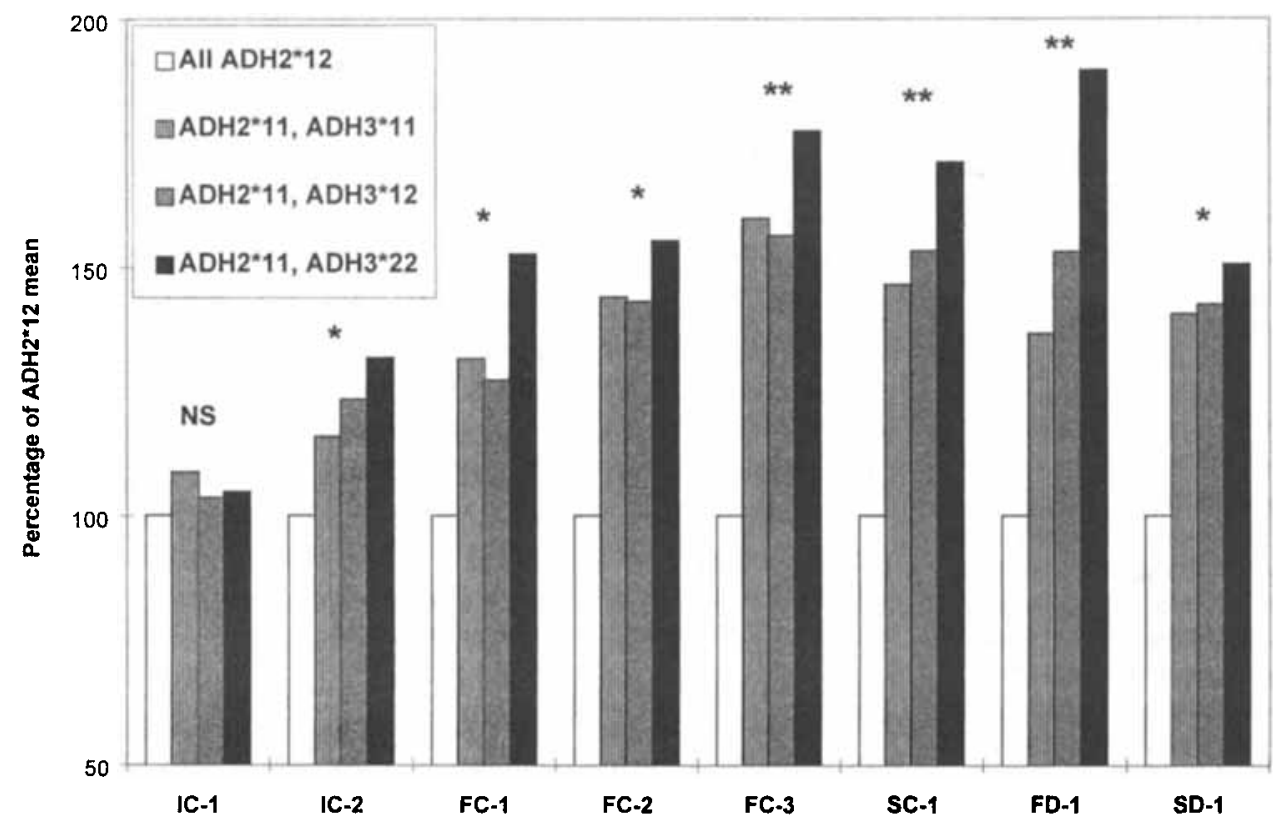

Fig. 1. Effects of combined $A D H 2 / A D H 3$ genotype on alcohol consumption and dependence measures in men. Consumption and dependence variables are indicated by $C$ or $D$, and the occasions by $I$ (initial study), $F$ (follow-up study), or S (SSAGA study). Values for group 1 (ADH2*12) have been standardized as 100 for each variable. $p$ values relate to a test for trend across groups 1 to 4 , as defined in the text: " $p<0.01 ; " p<0.05$; and NS, $p>0.05$. with a mean of 23 years; there were 199 men and 213 women. Recruitment of subjects was from a register of twins, from advertising, and from word of mouth. The number of potential subjects who declined to take part once the nature of the study was explained is not recorded, and there was a small number $(\sim 5 \%)$ of subjects who agreed to participate, but were unable to drink or retain the alcohol dose $(0.75 \mathrm{~g} / \mathrm{kg})$. Information is only available on subjects who were able to complete the experimental protocol. At that time (Initial Study), all subjects answered a questionnaire that included items on the usual number of drinks taken per week, and on the frequency and quantity of alcohol use (variables IC-1 and IC-2 in Tables 3 and 4 , and Fig. 1). This questionnaire was completed before the subjects drank any alcohol.

In a Follow-up Study in 1990 to 1992, we attempted to contact, and obtain blood samples for genotyping from, all subjects who had completed the Initial Study, 10 to 12 years previously. Those who were located and agrced to participate were asked to complete another questionnaire that included items on alcohol consumption (variables FC-1, FC-2, and FC-3) and on their lifetime experience of symptoms of alcohol dependence (variable FD-1). Three hundred thirty-four subjects (158 male, 176 female) completed this questionnaire and, at that time, their average age was 34 years.

In 1992 to 1996,336 of the subjects (159 male, 177 female; mean age: 37 years) also participated in a larger study of the genetics of alcohol dependence and comorbid conditions. ${ }^{18,19}$ This involved a structured interview (Semi-Structured Assessment for the Genetics of Alcoholism; $\mathrm{SSAGA}^{20}$ ) that included items on quantity and frequency of alcohol use (variable SC-1) and the number of dependence symptoms (variable SD-1). This interview allows diagnosis of alcohol dependence according to the Diagnostic and Statistical Manual of the American Psychiatric Association (DSM-III-R).

Therefore, the consumption and dependence information are covered by nine variables (those listed in Tables 3 and 4 ) and the DSM-III-R diagnosis of alcohol dependence. All items except the dependence diagnosis had large numbers of possible values and were treated as continuous variables. Because of the skewness of their distributions, all except the wcekly drinks category at follow-up were transformed to $\log _{10}(x+1)$ before use.

Estimates of consumption were significantly correlated ( $R 0.23$ to 0.83 ) both within and across occasions, as were estimates of dependence score; and consumption and dependence showed a considerable overlap. This is evidence for the reliability of the assessment of phenotype. The large proportion of men meeting DSM-III-R criteria for alcohol dependence is a frequent finding in community studies, ${ }^{18}$ but many such subjects do not seek treatment and are therefore omitted from studies that rely on clinical recruitment.

Blood was obtained for genotyping, either at the time of the Follow-up Study or after the SSAGA interview, from 369 subjects (176 male, 193 female). Genotypes for $A D H 2$ and $A D H 3$ were determined on DNA extracted from white blood cells, using the polymerase chain reaction and restriction digestion, followed by electrophoresis of the polymerase chain reaction products. ${ }^{21,22} A D H 2$ genotype was established for all 369 samples and $A D H 3$ for 367 . Genotypes for a further eight subjects were inferred from the genotypes of their monozygotic co-twins.

Data on ancestry were provided by 203 of the subjects as part of another project. They gave information on each of their four grandparents, and because of the large number of countries involved, the categories were combined into "Northern European" (including the UK, Eire, Germany, the Netherlands, Scandanavia, and also for this purpose Australia and New Zealand), "Southern European" (including Italy, Greece, Spain, Portugal, France, Turkey, and Lebanon), and Asian (from which there were only three reported grandparents). For the four categories of grandparent, the proportions reported as having a Southern European ancestry were $7.9 \%, 9.3 \%, 6.9 \%$, and $8.0 \%$. For further analysis, we classified individual subjects as having either $100 \%$ Northern European ancestry $(n=157)$ versus $<100 \%(n=24)$.

Statistical analysis was performed using BMDP Dynamic (BMDP Statistical Software, Inc., Los Angeles, CA) for analysis of variance and tests for trend across groups, or StatXact Turbo (Cytel Software Corporation, Cambridge, MA) for exact tests on contingency tables. Because the subjects were twins and therefore not genetically independent, tests for effects of genotype on the dependent variables were performed both with the subjects treated as independent observations of genotype, and after halving the number of degrees of freedom to allow for the fact that the subjects were related within twin pairs. This is a conservative approach; in either case, the estimates of the mean value for each genotype, and the estimate of the difference between them, are unbiased.

\section{RESULTS}

\section{Genotype Frequencies}

The frequencies of the observed $A D H 2$ and $A D H 3$ genotypes are shown in Table 1 , separately for men and 
Table 1. $A D H$ Genotype Frequencies, by $\operatorname{Sex}(M$, male; $F$, female)

\begin{tabular}{|c|c|c|c|c|}
\hline & $A D H 3 * 11$ & $A D H 3^{* 12}$ & $A D H 3 * 22$ & Total \\
\hline \multirow[t]{2}{*}{$A D H 2 * 11$} & $48 \mathrm{M}(26.5 \%)$ & $85 \mathrm{M}(47.0 \%)$ & $26 \mathrm{M}(14.4 \%)$ & $159 \mathrm{M}(87.8 \%)$ \\
\hline & 48 F $(24.7 \%)$ & $106 \mathrm{~F}(54.6 \%)$ & $29 F(14.9 \%)$ & $183 F(94.3 \%)$ \\
\hline \multirow[t]{2}{*}{$A D H 2^{*} 12$} & $9 \mathrm{M}(5.0 \%)$ & $12 \mathrm{M}(6.6 \%)$ & $1 \mathrm{M}(0.6 \%)$ & $22 \mathrm{M}(12.2 \%)$ \\
\hline & 7 F $(3.6 \%)$ & $4 F(2.1 \%)$ & OF $(0 \%)$ & 11 F $(5.7 \%)$ \\
\hline
\end{tabular}

Genotype frequencies differed significantly between men and women for $A D H 2$, but not for $A D H 3$. The frequency of the $A D H 2 * 12$ genotype was significantly higher in $A D H 3^{*} 12$ subjects (odds ratio: $2.33 ; 95 \% \mathrm{Cl}: 1.28-4.25$ ) and in $A D H 3^{*} 11$ subjects (odds ratio: $5.43 ; 95 \% \mathrm{Cl}: 1.63-18.06$ ) than in $A D H 3^{*} 22$ subjects.

Table 2. Lifetime DSM-III-R Alcohol Dependence by ADH2 Type

\begin{tabular}{lcc}
\hline & $A D H 2^{*} 11$ & $A D H 2^{*} 12$ \\
\hline Male affected & 36 & 1 \\
Male unaffected & 101 & 18 \\
& & \\
Female affected & 24 & 3 \\
Female unaffected & 144 & 7 \\
\hline
\end{tabular}

Breslow-Day statistic for heterogeneity of odds ratios (male/female) $=6.60,1$ df, $p=0.010$. Fisher's exact test (for difference in alcohol dependence by genotype): male, $p=0.032$ (one-tailed) or $p=0.046$ (two-tailed); female, $p=0.95$ (one-tailed).

women. The frequency of the $A D H 2^{*} 12$ genotype was $12.2 \%$ in the men, but only $5.7 \%$ in the women ( $p=0.029$, Fisher's exact test). No subjects were homozygous for $A D H 2^{*} 2$, and there were no occurrences of $A D H 2 * 3$.

Frequencies of $A D H 3^{*} 11,12$, and 22 were $31.5 \%, 53.6 \%$, and $15.0 \%$ in the men and $28.3 \%, 56.7 \%$, and $14.9 \%$ in the women (no significant sex difference). Subjects with $A D H 3^{*} 11$ genotype were most likely, and subjects with $A D H 3^{*} 22$ were least likely, to be $A D H 2^{*} 12$; the trend across $A D H 3$ groups was significant ( $p=0.0051$, twotailed, by the StatXact method based on the CochranArmitage test).

\section{Genotype and Reported Ancestry}

The $A D H 2 * 2$ gene frequency was $1.9 \%$ in subjects of $100 \%$ Northern European descent and $12.5 \%$ in those with at least one non-Northern European grandparent.

\section{Effects of ADH2 Type}

There was a significant heterogeneity in the effect of $A D H 2$ genotype on dependence between men and women; therefore, results for the two sexes were analyzed separately (Table 2). Among the men, $26.3 \%$ of those with $A D H 2^{*} 11$ genotype, but only $5.3 \%$ of those with $A D H 2 * 12$ genotype, met DSM-III-R criteria for lifetime alcohol dependence. This is a significant difference [Fisher's exact test, $p=0.032$ (one-tailed, with the expectation of a lower risk in $A D H 2 * 12$ subjects) or 0.046 (two-tailed); odds ratio: 6.41]. However, no significant effect of $A D H 2$ on alcohol dependence was found among the women $(p=0.95)$. Data from men and women were therefore analyzed separately for the quantitative variables.

Table 3 shows that nearly all the quantitative measures of consumption and dependence symptoms were significantly affected by $A D H 2$ genotype in men. All eight measures showed higher values in the $A D H 2^{*} 11$ men, with three $p$ values between 0.05 and 0.01 and three below 0.01 . However, $A D H 2$ genotype had no detectable effects on alcohol consumption or number of dependence symptoms in women. The values for $\eta^{2}$ (the proportion of the total phenotypic variance explained by variation in $A D H 2$ genotype) in Table 3 show that up to $6 \%$ of the variance in alcohol consumption, or $\sim 10$ to $25 \%$ of the genetic variance in men based on estimates of the heritability of quantity and frequency consumption measures for Australian males, ${ }^{23}$ can be accounted for by variation at this locus.

\section{Effects of ADH3 Type}

The effects of $A D H 3$ type on the various measures of alcohol consumption and alcohol-related problems are shown in Table 4. Analysis of variance based on $A D H 3$ genotype alone showed only one significant result for the men and three (but not in the expected direction) for the women. However, for 7 of 8 variables, the $A D H 3^{*} 22$ men had the highest scores of any of the genotype groups.

\section{Combined Effects of $\mathrm{ADH} 2$ and $\mathrm{ADH} 3$ Genotypes}

As discussed previously, prior work on genotype and dependence, and on the in vitro properties of purified $\mathrm{ADH}$ isoenzymes, suggests that alcohol use would increase in the order $A D H 2^{*} 12, A D H 3^{*} 11<A D H 2^{*} 12, A D H 3^{*} 12<$ $A D H 2^{*} 12, A D H 3^{*} 22<A D H 2^{*} 11, A D H 3^{*} 11<A D H 2^{*} 11$, $A D H 3^{*} 12<A D H 2^{*} 11, A D H 3^{*} 22$. Male subjects were therefore divided into four groups: (1) all $A D H 2^{*} 12$ subjects ( $n=$ 22; there were insufficient subjects in this group to allow subdivision by $A D H 3$ type); (2) $A D H 2^{*} 11, A D H 3^{*} 11$ ( $n=$ 48); (3) $A D H 2^{*} 11, A D H 3^{*} 12(n=85)$; and (4) $A D H 2^{*} 11$, $A D H 3^{*} 22(n=26)$, and tests for trend in each of the continuous consumption or dependence variables were performed. The results (Fig. 1) show that a significant trend in the expected direction occurred for 7 of 8 measures of alcohol consumption or dependence. The risk of DSM-III-R dependence was also lowest in group 1 and highest in group 4 (odds ratio: 8.61 ).

\section{Ancestry Effects}

Because of the difference in $A D H 2 * 2$ allele frequency between subjects of Northern and Southern European ancestry, it became important to determine whether there was a difference in the quantitative alcohol consumption or problem variables between these groups. Only $A D H 2^{*} 11$ subjects were used in this analysis, to avoid confounding any true effects of $A D H 2^{*} 2$ with the ancestry information. For each of the eight variables, the mean was greater in the all-North-European grandparents group $(n=151)$ than in the other group $(n=18)$. However, the difference was only statistically significant $(p=0.044)$ for one of the variables (FC-1). 
Table 3. Mean Values for Alcohol Consumption or Dependence Measures by ADH2 Genotype

\begin{tabular}{|c|c|c|c|c|c|c|c|c|c|c|c|c|}
\hline & \multicolumn{6}{|c|}{ Male } & \multicolumn{6}{|c|}{ Female } \\
\hline & $A D H_{2} * 11$ & $\mathrm{AOH} 2^{*} 12$ & $F$ & $d f$ & $p$ & $\eta^{2}$ & $A D H 2 * 11$ & $A D H 2 * 12$ & $F$ & $d f$ & $p$ & $\eta^{2}$ \\
\hline $\begin{array}{l}\text { Sum of weekly drinks in 1979- } \\
1981 \text { (IC-1) }\end{array}$ & 0.942 & 0.896 & 0.17 & 1,180 & 0.677 & 0.001 & 0.724 & 0.736 & 0.01 & 1,191 & 0.925 & 0.000 \\
\hline $\begin{array}{l}\text { Quantity } \times \text { frequency measure in } \\
1979-1981(\text { IC- } 2)\end{array}$ & 1.317 & 1.078 & 3.61 & 1,176 & 0.059 & 0.020 & 1.113 & 0.982 & 0.69 & 1,192 & 0.407 & 0.004 \\
\hline $\begin{array}{l}\text { Consumption in past week at } \\
\text { follow-up (FC-1) }\end{array}$ & 0.968 & 0.731 & 4.90 & 1,152 & 0.028 & 0.031 & 0.641 & 0.761 & 0.68 & 1,173 & 0.409 & 0.004 \\
\hline $\begin{array}{l}\text { Quantity } \times \text { frequency measure at } \\
\text { follow-up }(\mathrm{FC}-2)\end{array}$ & 0.904 & 0.622 & 9.72 & 1,144 & 0.002 & 0.063 & 0.693 & 0.645 & 0.15 & 1,160 & 0.700 & 0.001 \\
\hline $\begin{array}{l}\text { Weekly drinks category at follow- } \\
\text { up (FC-3) }\end{array}$ & 3.47 & 2.16 & 10.57 & 1,156 & 0.001 & 0.064 & 2.51 & 2.30 & 0.27 & 1,175 & 0.602 & 0.002 \\
\hline $\begin{array}{l}\text { Quantity } \times \text { frequency measure at } \\
\text { SSAGA (SC-1) }\end{array}$ & 0.869 & 0.560 & 11.21 & 1,158 & $0.00 t$ & 0.066 & 0.624 & 0.405 & 3.65 & 1,175 & 0.058 & 0.020 \\
\hline $\begin{array}{l}\text { No. of symptoms positive at } \\
\text { follow-up (FD-1) }\end{array}$ & 0.457 & 0.296 & 4.63 & 1,156 & 0.033 & 0.029 & 0.328 & 0.333 & 0.00 & 1,175 & 0.952 & 0.000 \\
\hline $\begin{array}{l}\text { No. of symptoms positive at } \\
\text { SSAGA (SD-1) }\end{array}$ & 0.606 & 0.421 & 6.46 & 1,150 & 0.012 & 0.041 & 0.427 & 0.425 & 0.00 & 1,167 & 0.985 & 0.000 \\
\hline
\end{tabular}

Consumption and dependence variables are indicated by $\mathrm{C}$ or D, and the occasions by I (initial study), F (follow-up study), or S (SSAGA study). All variables except FC-3 are log-transformed.

Note: for male subjects, 3 of 8 comparisons significant at $p<0.01,3$ of 8 significant at $p<0.05,1$ significant at $<0.10$, and 1 NS. This is still the case if $p$ values are calculated from the same $F$ statistics but with half the degrees of freedom. $p$ values $<0.05$ are shown in bold font.

Table 4. Mean Values for Alcohol Consumption or Dependence Measures by $A D H 3$ Genotype

\begin{tabular}{|c|c|c|c|c|c|c|c|c|c|c|c|c|}
\hline & \multicolumn{6}{|c|}{ Male } & \multicolumn{6}{|c|}{ Female } \\
\hline & $A D H 3 * 11$ & $A D H 3^{*} 12$ & $A D H 3^{*} 22$ & $F$ & $d f$ & $p$ & $A D H 3 * 11$ & $A D H 3^{*} 12$ & $A D H 3^{*} 22$ & $F$ & $d f$ & $p$ \\
\hline $\begin{array}{l}\text { Sum of weekly drinks in } 1979-1981 \\
(I-C 1)\end{array}$ & 0.959 & 0.927 & 0.939 & 0.08 & 2,178 & 0.924 & 0.720 & 0.714 & 0.796 & 0.51 & 2,189 & 0.599 \\
\hline $\begin{array}{l}\text { Quantity } \times \text { frequency measure in } \\
1979-1981(1-C 2)\end{array}$ & 1.236 & 1.290 & 1.409 & 0.86 & 2,174 & 0.423 & 1.091 & 1.094 & 1.204 & 0.59 & 2,190 & 0.557 \\
\hline $\begin{array}{l}\text { Consumption in past week at follow- } \\
\text { up }(F-C 1)\end{array}$ & 0.924 & 0.903 & 1.110 & 1.99 & 2,151 & 0.141 & 0.775 & 0.592 & 0.617 & 3.15 & 2,171 & 0.045 \\
\hline $\begin{array}{l}\text { Quantity } \times \text { frequency measure at } \\
\text { follow-up }(F-C 2)\end{array}$ & 0.893 & 0.877 & 0.962 & 0.55 & 2,143 & 0.579 & 0.844 & 0.680 & 0.666 & 3.65 & 2,158 & 0.028 \\
\hline $\begin{array}{l}\text { Weekly drinks category at follow-up } \\
\text { (F-C3) }\end{array}$ & 3.267 & 3.202 & 3.792 & 1.16 & 2,155 & 0.315 & 2.857 & 2.340 & 2.407 & 2.91 & 2,173 & 0.057 \\
\hline $\begin{array}{l}\text { Quantity } \times \text { frequency measure from } \\
\text { SSAGA (S-C1) }\end{array}$ & 0.755 & 0.805 & 0.942 & 1.76 & 2,156 & 0.175 & 0.697 & 0.542 & 0.563 & 3.12 & 2,173 & 0.047 \\
\hline $\begin{array}{l}\text { No. of symptoms positive at follow- } \\
\text { up (F-D1) }\end{array}$ & 0.376 & 0.433 & 0.570 & 3.16 & 2,155 & 0.045 & 0.281 & 0.294 & 0.355 & 0.69 & 2,173 & 0.503 \\
\hline $\begin{array}{l}\text { No. of symptoms positive in SSAGA } \\
\text { (S-D1) }\end{array}$ & 0.587 & 0.573 & 0.608 & 0.14 & 2,148 & 0.869 & 0.486 & 0.396 & 0.460 & 1.46 & 2,165 & 0.235 \\
\hline
\end{tabular}

Consumption and dependence variables are indicated by C or D, and the occasions by I (initial study), F (follow-up study), or S (SSAGA study). All variables except FC-3 are log-transformed.

Nevertheless, this result fuels the suspicion that the relationship between $A D H 2$ genotype and drinking habits or problems that we have observed is confounded by ethnic stratification. The best way to avoid this confounding is to rely only on within-family comparisons. Unfortunately, in our sample, we only have five pairs of same-sex dizygotic twins, where one twin was $A D H 2^{*} 11$ and the other was $A D H 2 * 12$. We compared the eight alcohol consumption and problem variables within each of these five pairs, on the hypothesis that the $A D H 2^{*} 11$ twin would have the higher values. Of the 40 possible comparisons, 29 showed a higher result for the $A D H 2^{*} 11$ twin, 5 showed a lower result, and there were 6 ties. In all five pairs, there was a majority (ranging from 4-2 to 7-0) of higher results in the $A D H 2 * 11$ subject. Although the number of pairs is small, the probability that in all five $A D H 2$ discordant pairs the $A D H 2 * 11$ genotype would be the heavier drinking twin is only 1 in $32(p=0.031)$.

\section{DISCUSSION}

\section{ADH, Alcohol Consumption, and Alcohol Dependence}

$A D H$ genotype effects have been reported consistently in studies on Japanese or Chinese subjects, and are assumed to be mediated by differences in alcohol metabolism. The aim of this study was to test for effects of $A D H$ genotype on alcohol consumption, alcohol-related problems, and alcohol dependence in men and women of European descent.

We have found that $A D H 2$ genotype does influence alcohol dependence, consumption, and problems in the men; 
but, variation in this factor has nonsignificant effects in women of the same background. $A D H 3$, which has effects on alcohol dependence that are almost as great as those of $A D H 2$ in Asians, had mainly nonsignificant effects (or effects contrary to expectation) in both men and women (Table 4), but there is some evidence for $A D H 3$ effects in the male $A D H 2^{*} 11$ subjects (Fig. 1). These results extend our knowledge of genetic factors influencing alcohol use and dependence to a different population group (Europeans), and to alcohol use in the general population.

The consistent direction of these effects across several occasions of study spread over 15 years reinforces our general conclusions, although the nonsignificant results from the initial phase suggest that genetic factors may be overcome by other influences in younger men. The effects of $A D H 2$ genotype at initial study in 1979 to 1981 , when the average age of the subjects was 23 , are less than those seen later when the subjects were 12 to 15 years older. It has previously been shown that stability of alcohol consumption is greater after age $25,{ }^{24}$ and social or other non- $A D H$ related influences may predominate among the young.

Despite the comparatively small number of $A D H 2^{*} 12$ subjects, evidence of effects on both dependence and consumption was found. Because the frequency of $A D H 2 * 2$ is $<10 \%$ among Europeans, ${ }^{25}$ and because genotyping techniques capable of handling large numbers of samples have only recently become available, previous studies that produced negative results ${ }^{12-15}$ may have done so because of insufficient power. Negative results may also have arisen from comparing subjects with alcoholic liver disease with controls who are not alcohol-dependent, because $A D H 2$ variation has the opposite effects on dependence and alcoholic liver disease. ${ }^{10}$

For $A D H 3$, where the gene frequencies of $A D H 3^{*} 1$ and 2 are nearly equal in Europeans and the power to detect differences between genotypes is greater, one previous study showed negative results ${ }^{15}$ in contrast to multiple positive reports on Asians. ${ }^{1,3,4,7}$

\section{Male-Female Differences in ADH2 Effects}

There are a number of possible reasons why significant effects were found in men, but not in women. First, some important aspect of alcohol metabolism could differ between men and women and nullify the effects of $A D H 2$. Although the rate of decrease in blood alcohol concentration after a test dose was the same in men and women in this group of subjects, ${ }^{16}$ there have been a number of claims that sex hormones affect alcohol metabolism ${ }^{26}$ or $\mathrm{ADH}$ activity, ${ }^{27}$ or are associated with differences in post-alcohol acetaldehyde concentrations. ${ }^{28}$ In mice,${ }^{29}$ some but not all inbred strains show differences in hepatic ADH activity between males and females.

Second, an effect might be missed because of the lower mean and narrower range of alcohol consumption in women than men, or because of insufficient $A D H 2^{*} 12$ women in our study. As seen in Table 1, the proportion of $A D H 2^{*} 12$ subjects was significantly greater among the men, either because $A D H 2^{*} 12$ women were underrepresented or because $A D H 2 * 12$ men were overrepresented. Women who are genetically disposed toward low consumption might have chosen not to participate in the initial alcohol challenge procedure, which determined admission to the study group. The smaller number of $A D H 2 * 12$ women would have reduced our power to detect $A D H 2$ genotype effects on drinking in women.

Most previous reports do not compare the effects of $A D H$ in men and women. Of the nine cited studies ${ }^{1-9}$ from China and Japan, five appear to have studied only men and three have pooled results from men and women without comment on the justification for this procedure. The one study that did consider women's results separately ${ }^{5}$ reported that the women drank $<5 \%$ of the average male amount, and "there were no significant differences between the drinking patterns of women with any of the $A D H 2$ or $A L D H 2$ genotypes." The difference in alcohol intake between men and women was less extreme in our study; at each of the three times studied, the geometric mean of alcohol intake was approximately twice as great in the men as in the women.

Study of larger numbers of women, without the selection procedure imposed on our subjects by the alcohol challenge study, should decide between the negative results being due to lack of power to detect effects or true sex differences.

\section{Combined Effects of $\mathrm{ADH} 2$ and $\mathrm{ADH} 3$ Genotypes}

The expectation from previous reports was that $A D H 2$ type would have a stronger effect than $A D H 3$ type, and that those most at risk would be the 11 homozygotes for $A D H 2$ and the 22 homozygotes for $A D H 3$. Oriental $A D H 2^{*} 11$ subjects have approximately eight times the risk of alcohol dependence of $A D H 2^{*} 22$, whereas $A D H 3^{*} 11$ subjects have around half the risk of $A D H 3^{*} 22 .^{3}$

$A D H 3$ effects were much smaller than $A D H 2$ effects in this study (as anticipated), but when the subjects were grouped by $A D H 2$ and $A D H 3$ genotype in the order which is predicted (from previous reports) to show increasing alcohol consumption or dependence, a significant trend in the expected direction was present for nearly all the measures. This is also the decreasing order of in vitro enzyme activity.

\section{Possible Effects of Population Stratification}

There was suggestive evidence both that $A D H 2 * 2$ is more common in people of partial Southern European descent than in people of entirely Northern European descent (see also Ref. 25), and that alcohol consumption and problems were lower in the Southern group. It is therefore possible that population stratification is producing the associations between $A D H$ genotype and phenotype. Unfortunately, we do not have complete ancestry data for all our 
subjects and, even if it was available, it would not necessarily give a definitive answer.

The way to avoid such problems is to use only withinfamily comparisons. Having genotype information from parents allows use of the transmission disequilibrium test ${ }^{30}$ or, in this case, we make use of siblings discordant for $A D H 2$ genotype. Intrapair comparisons from the five dizygotic twin pairs discordant for $A D H 2$ type do not support population stratification as the sole explanation of our results. Rather, they point to a genuine effect of the $A D H 2 * 2$ allele as aversive to drinking and protective against alcohol-related problems.

However, it is clear that a much larger sample of $A D H 2$ discordant sibling pairs, with full drinking histories, is needed to settle this issue. We are currently assembling such a sample. It is perhaps worth noting that previous studies on association between alcohol metabolizing enzymes and drinking behavior in Asian populations are not necessarily free of the population stratification problem.

\section{Conclusions}

These results support the importance of some aspect of alcohol metabolism in influencing consumption and dependence, presumably by affecting the nature of the "alcohol experience." They are consistent with the hypothesis that the rate of generation of acetaldehyde from ethanol may be a significant determinant of alcohol use, because the more active isoenzymes of $\mathrm{ADH}$ are the ones associated with lowest alcohol consumption and the least risk of alcohol dependence. Nevertheless, further consideration of the mechanism of this effect is required because $A D H$ genotype has only small effects on the rate of ethanol metabolism measured in vivo, ${ }^{31,32}$ and because increased postalcohol acetaldehyde concentrations in non-ALDH-deficient subjects carrying $A D H 2^{*} 2$ or $A D H 3^{*} 1$ have not been demonstrated. Studies using family structures are required to rule out effects of population stratification.

\section{ACKNOWLEDGMENT}

We would like to thank Theresa Pangan and John Pearson for data processing, and Sue Mason and Pam Saunders for twin liaison and blood collection. We thank Dixie Statham for coordinating the interview phase of the project, and Stephen Dinwiddie and Michael Dunne for their assistance with interview development.

\section{REFERENCES}

1. Thomasson HR, Edenberg HJ, Crabb DW, Mai XL, Jerome RE, Li TK, Wang SP, Lin YT, Lu RB, Yin SJ: Alcohol and aldehyde dehydrogenase genotypes and alcoholism in Chinese men. Am J Hum Genet $8: 677-681,1991$

2. Thomasson HR, Crabb DW, Edenberg HJ, Li T-K, Hwu H-G, Chen C-C, Yeh E-K, Yin S-J: Low frequency of the $A D H 2 * 2$ allele among Atayal natives of Taiwan with alcohol use disorders. Alcohol Clin Exp Res 18:640-643, 1994

3. Higuchi S: Polymorphisms of ethanol metabolising enzyme genes and alcoholism. Alcohol Alcohol 29(Suppl. 2):29-34, 1994
4. Maezawa Y, Yamauchi M, Toda G, Suzuki H, Sakurai S: Alcoholmetabolizing enzyme polymorphisms and alcoholism in Japan. Alcohol Clin Exp Res 19:951-954, 1995

5. Muramatsu T, Wang ZC, Fang YR, Hu KB, Yan H, Yamada K, Higuchi S, Harada S, Kono $\mathrm{H}$; Alcohol and aldehyde dehydrogenase genotypes and drinking behavior of Chinese living in Shanghai. Hum Genet 96:151-154, 1995

6. Nakamura K, Suwaki H, Matsuo Y, Ichikawa Y, Miyatake R, Iwahashi K: Association between alcoholics and the genotypes of $A L D H 2$, $A D H 2, A D H 3$ as well as P-4502E1. Arukoru Kenkyuto Yakubutsu Ison 30:33-42, 1995

7. Tanaka F, Shiratori Y, Yokosuka O, Imazeki F, Tsukada Y, Omata M: High incidence of $A D H 2^{*} 1 / A L D H 2^{*} 1$ genes among Japanese alcohol dependents and patients with alcoholic liver disease. Hepatology 23:234239, 1996

8. Tanaka F, Shiratori Y, Yokosuka O, Imazeki F, Tsukada Y, Omata M: Polymorphism of alcohol-metabolizing genes affects drinking behavior and alcoholic liver disease in Japanese men. Alcohol Clin Exp Res 21: 596-601, 1997

9. Shen Y-C, Fan J-H, Edenberg HJ, Li T-K, Cui Y-H, Wang Y-F, Tian C-H, Zhou C-F, Zhou R-L, Wang J, Zhao Z-L, Xia G-Y: Polymorphism of $A D H$ and $A L D H$ genes among four ethnic groups in China and effects upon the risk for alcoholism. Alcohol Clin Exp Res 21:1272-1277, 1997

10. Whitfield JB: Meta-analysis of the effects of alcohol dehydrogenase genotype on alcohol dependence and alcoholic liver disease. Alcohol Alcohol 32:613-619, 1997

11. Bosron WF, Li T-K: Genetic polymorphism of human liver alcohol and aldehyde dehydrogenases, and their relationship to alcohol metabolism and alcoholism. Hepatology 6:502-510, 1986

12. Ricciardi BR, Saunders JB, Williams R, Hopkinson DA: Hepatic $A D H$ and ALDH isoenzymes in different racial groups and in chronic alcoholism. Pharmacol Biochem Behav 18(Suppl. 1):61-65, 1983

13. Wermuth B, Ernst E, von Wartburg JP, Speck R, Schwarzenbach F, Lauterburg B: Determination of alcohol dehydrogenase genotype: No correlation between isoenzyme pattern and liver cirrhosis. Schweizer Mediziner Wochenschrift 121:1880-1882, 1991

14. Vidal F, Perez J, Panisello J, Toda R, Gutierrez C, Richart C: Atypical liver alcohol dehydrogenase in the Spanish population: Its relation with the development of alcoholic liver disease. Alcohol Clin Exp Res 17:782-785, 1993

15. Gilder FJ, Hodgkinson S, Murray RM: $A D H$ and $A L D H$ genotype profiles in Caucasians with alcohol-related problems and controls. Addiction 88:383-388, 1993

16. Martin NG, Perl J, Oakeshott JG, Gibson JB, Starmer GA, Wilks AV: A twin study of ethanol metabolism. Behav Genet 15:93-109, 1985

17. Martin NG, Oakeshott JG, Gibson JB, Starmer GA, Perl J, Wilks AV: A twin study of psychomotor and physiological responses to an acute dose of alcohol. Behav Genet 15:305-347, 1985

18. Heath AC, Bucholz KK, Slutske WS, Madden PAF, Dinwiddie SH, Dunne MP, Statham DJ, Whitfield JB, Martin NG, Eaves LJ: The assessment of alcoholism in surveys of the general community: What are we measuring? Some insights from the Australian Twin Panel Survey. Int Rev Psychiatry 6:295-307, 1994

19. Heath AC, Bucholz KK, Madden PAF, Dinwiddie SH, Slutske WS Statham DJ, Dunne MP, Whitfield JB, Martin NG: Genetic and environmental contributions to alcohol dependence risk in a national twin sample: Consistency of findings in women and men. Psychol Med 27:1381-1396, 1997

20. Bucholz KK, Cadoret R, Cloninger CR, Dinwiddic SH, Hesselbrock VM, Numberger JI Jr, Reich T, Schmidt I, Schuckit MA: A new, semi-structured psychiatric interview for use in genetic linkage studies: A report on the reliability of the SSAGA. J Stud Alcohol 55:149-158, 1994

21. von Wartburg JP, Gennari K, Muellener D, Wermuth B: Determination of the genotype of human class I alcohol dehydrogenase, in Kuriyama K, Takada A, Ishii H (eds): Biomedical and Social Aspects of Alcohol and Alcoholism. Amsterdam, Excerpta Medica, 1988, pp 35-38 
22. Xu Y, Carr LG, Bosron WF, Li T-K, Edenberg HJ: Genotyping of human alcohol dehydrogenases at the $A D H 2$ and $A D H 3$ loci following DNA sequence amplification. Genomics 2:209-214, 1988

23. Heath AC, Meyer J, Jardine R, Martin NG: The inheritance of alcohol consumption patterns in a general population twin sample. II. Determinants of consumption frequency and quantity consumed. J Stud Alcohol 52:425-433, 1991

24. Heath AC: Genetic influences on drinking behavior in humans. In: Begleiter H, Kissin B (eds): The Genetics of Alcoholism. Oxford, Oxford University Press, 1995, pp 82-121

25. Goedde HW, Agarwal DP, Fritze G, Meier-Tackmann D, Singh S, Beckmann G, Bhatia K, Chen LZ, Fang B, Lisker R: Distribution of $A D H 2$ and $A L D H 2$ genotypes in different populations. Hum Genet 88: 344-346, 1992

26. Mezey E, Oesterling JE, Potter JJ: Influence of male hormones on rates of ethanol elimination in man. Hepatology 8:742-744, 1988

27. Mardh G, Falchuk KH, Auld DS, Vallee B: Testosterone alloster- ically regulates ethanol oxidation by homo- and heterodimeric $\gamma$-subunitcontaining isozymes of human alcohol dehydrogenase. Proc Natl Acad Sci USA 83:2836-2840, 1986

28. Eriksson CJ, Fukunaga T, Sarkola T, Lindholm H, Ahola L: Estrogen-related acetaldehyde elevation in women during alcohol intoxication. Alcohol Clin Exp Res 20:1192-1195, 1996

29. Rao UN, Aravindakshan M, Satyanarayan V, Chauhan PS: Genotype - and gender-dependent hepatic alcohol dehydrogenase (ADH) activity in developing mice. Alcohol 14:527-531, 1997

30. Allison DB: Transmission disequilibrium tests for quantitative traits. Am J Hum Genet 60:676-690, 1997

31. Yamamoto K, Ueno Y, Mizoi Y, Tatsuno Y: Genetic polymorphism of alcohol and aldehyde dehydrogenases and the effects on alcohol metabolism. Arukoru Kenkyuto Yakubutsu Ison 28:13-25, 1993

32. Whitfield JB: $A D H$ and $A L D H$ genotypes in relation to alcohol metabolic rate and sensitivity. Alcohol Alcohol 29(Suppl. 2): 59-65, 1994 